\title{
PENGARUH KETEBALAN KOMPOSIT MATRIK RESIN DENGAN PENGUAT KULIT ECENG GONDOK (EICHHORNIA CRASSIPES) YANG DIANYAM TERHADAP KEMAMPUAN BALISTIK
}

\author{
TopanAsmoro Aji, Helmy Purwanto, Sri Mulyo Bondan Respati \\ Jurusan Teknik Mesin Univ. Wahid Hasyim Semarang \\ JL. Menoreh Tengah 2, Semarang 50236, Indonesia \\ Email : topangbastian@gmail.com
}

\begin{abstract}
Abstrak
Penggunaan material komposit dengan pengisi (filler) serat alam kulit eceng gondok (EichhorniaCrassipes) berpotensi sebagai bahan teknik alternatif. Komposit mempunyai keunggulan tersendiri dibanding dengan bahan teknik alternatif lain, karena sifat komposit yang memiliki kekuatan yang bisa diatur (tailorability), memiliki kekuatan lelah (fatigue) yang baik, memiliki kekuatan jenis (strenght/weight) yang tinggi dan tahan korosi. Tujuan penelitian ini adalah untuk mengetahui dan menganalisa pengaruh ketebalan komposit matrik resin dengan penguat kulit eceng gondok yang disusun anyam terhadap ketahanan balistik. Kulit serat direndam larutan $\mathrm{NaOH} \mathrm{5 \%} \mathrm{dan} \mathrm{tanpa} \mathrm{perlakuan} \mathrm{selama} 1$ jam. Komposit matrik dibuat dengan pengisi kulit eceng gondok dan resin dengan perbandingan $89 \%$ resin dan $11 \%$ kulit eceng gondok. Variabel ketebalan yang digunakan yaitu 3 mm, 6 mm dan $10 \mathrm{~mm}$. Hasil uji tarik pilinan kulit eceng gondok tanpa perendaman memiliki kekuatan tarik sebesar 2,0756 kg/mm ${ }^{2}$. dan pilinan kulit eceng gondok dengan perendaman $\mathrm{NaOH} 5 \%$ memiliki kekuatan tarik sebesar $3,5512 \mathrm{~kg} / \mathrm{mm}^{2}$. Hasil uji balistik menunjukkan komposit dengan ketebalan $10 \mathrm{~mm}$ mampu menahan laju proyektil, sedangkan komposit dengan ketebalan $3 \mathrm{~mm}$ dapat tertembus proyektil. Dari hasil penelitian semakin tebal panel komposit maka semakin mampu menahan laju balistik.
\end{abstract}

Kata kunci: Kulit eceng gondok, ketebalan komposit tahan balistik.

\section{PENDAHULUAN}

Penggunaan material komposit dengan pengisi (filler) serat alam mulai banyak dikenal dalam industry manufaktur. Material yang ramah lingkungan, mampu di daur ulang, serta terurai sendiri oleh alam merupakan tuntutan teknologi sekarang ini. Salah satu material yang diharapkan mampu memenuhi hal tersebut adalah material komposit dengan material pengisi serat alam. Serat alam yang dapat diperoleh dengan mudah salah satunya adalah kulit enceng gondok.

Eceng gondok (Eichhorniacrassipes) adalah tanaman yang tumbuh di perairan yang berlumpur. Eceng gondok tumbuh dengan cepat sehingga perlu penanganan agar tidak mengganggu dan merusak ekosistem lingkungan, salah satu alternatifnya adalah dengan pembuatan bahan untuk komposit. Serat eceng gondok merupakan salah satu material natural fiber yang cocok dalam alternative dalam pembuatan komposit (Prasetyaningrum dkk, 2009). Dalam pembuatan komposit plastic berpenguat (fiber reinforced plastic) matriks yang sering digunakan adalah thermosetting polimer atau lebih dikenal dengan resin. Prasetyaningrum dkk, (2009). Salah satu faktor penting yang menentukan karakteristik mekanik dari komposit yaitu perbandingan serat dan matriknya (Gibson, 1994)

Susunan serat eceng gondok pada komposit berpengaruh terhadap kekuatan komposit. Serat eceng gondok yang disusun dengan sudut $0^{\circ}$ mempunyai kekuatan tarik lebih besar dibandingkan serat eceng gondok dengan susunan sudut $45^{\circ}$ pada matrik polyeste (Yudo dan Kiryanto 2007).

Rekayasa bahan baku dan limbah kokon telah dibuat rompi anti peluru dan mampu menahan laju peluru dari senapan M16 pada jarak 100mm (Moeliono dan Siregar 2012). Zubaidi, dkk (2009) melakukan penelitian tentang pembuatan rompi anti peluru menggunakan bahan dasar serat polyester. Dari hasil uji menunjukkan bahwa panel dari serat polyester dapat mencapai level II pada standar internasional NU -0101.04. Dibanding panel dari komposit serat rami, panel dari serat polyester mempunyai kelebihan dalam hal kelenturan, kestabilan, dan lebih nyaman dalam pemakaiannya. Prinsip kerja rompi anti peluru adalah mengurangi sebanyak mungkin lontran energi kinetik. Batas maksimal penekanan tidak boleh lebih dari $4,4 \mathrm{~cm}(44 \mathrm{~mm})$ agar tidak 
membahayakan keselamatan jiwa (NIJ-0101.04. 2001).

Tujuan dari penelitian ini adalah untuk mengetahui dan menganalisa karakteristik fisik dan kekuatan tarik kulit eceng gondok dan pengaruh ketebalan komposit matrik resin dengan penguat kulit eceng gondok yang disusun anyam terhadap ketahanan balistik.

\section{METODELOGI}

Bahan yang digunakan dalam penelitian ini adalah kulit eceng gondok, resin bening $5120 \mathrm{P}$, katalis (MEKPO), aquadest, $\mathrm{NaOH}$. Alat yang digunakan adalah cetakan ukuran $\left(15 \times 15 \times 1 \mathrm{~cm}^{3}\right)$, gelas ukur, aluminium foil, timbangan digital, alat anyaman, gunting, kuas, suntikan, sikat gerinda, amplas, gerinda, skrap, jangka sorong, mesin uji tarik, chronograph, stand spesimen, peluru senapan.

Pembuatan dan perlakuan alkalisasi yaitu siapkan batang eceng gondok yang berusia \pm 8 bulan, keringkan batang eceng gondok kemudian pisahkan daging dari kulitnya sampai menjadi lembaran kulit eceng gondok dan sikat menggunakan sikat sampai menjadi lembaran kecil dan panjang kemudian keringkan. Perlakuan alkalisasi rendam lembaran kecil kulit pada $\mathrm{NaOH} 5 \%$ yang sudah dilarutkan menggunakan Aquadest $500 \mathrm{ml}$ selama 1 jam, dan angkat keringkan dengan suhu kamar selama \pm 8 jam.

Pembuatan anyaman kulit eceng gondok yaitu pilinan kulit eceng gondok ikat pada kedua sisi paku alat anyam sampai semua sisi paku terikat dengan pilinan kulit eceng gondok, anyam kulit eceng gondok dengan jarak 2 anyaman pilinan kulit yang tegak lurus, lakukan sampai alat anyaman penuh seperti pada Gambar 1.

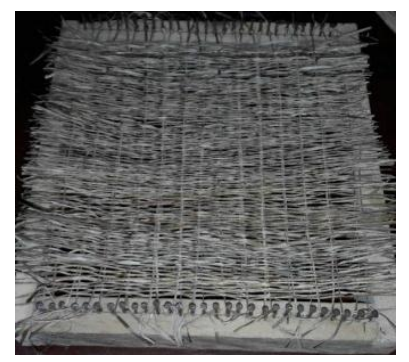

\section{Gambar 1. Anyaman kulit eceng gondok}

Pembutan spesimen komposit untuk uji balistik adalah cetakan diolesi dengan kit agar spesimen komposit yang sudah kering tidak lengket, sediakan resin sebanyak $201 \mathrm{ml}$ pada gelas ukur yang sudah ditambah katalis sebanyak $2 \mathrm{ml}$, tungkan kedalam cetakan dan masukkan anyaman, tambah resin \pm 5 untuk mengurangi void karena kekurangan volume matrik, tutup cetakan rapat dengan kaca tunggu hingga kering.

$$
\text { Pembuatan spesimen uji tarik }
$$
disesuaikan dengan standar ASTM D 638M84,dapat dilihat pada Gambar 2.

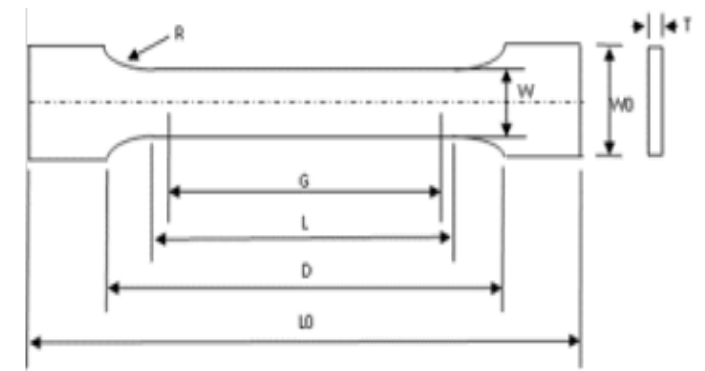

\section{Gambar 2.Spesifikasi cetakan ASTM D 638M-84}

Pengujian balistik yaitu pengujian dimana panel komposit ditembak senapan pada jarak $5 \mathrm{~m}$. Adapun langkah-langkahnya yaitu mencari rata-rata kecepatan peluru dengan cara menembakkan peluru pada chronograph pada jarak $2 \mathrm{~m}$ kemudian siapkan panel komposit dan letakkan pada stand spesimen, pasang chronograph. Ambil jarak $5 \mathrm{~m}$ dari panel komposit lalu tembak panel sebanyak 3 kali pada tempat yang berbeda. Skema pengujian balistik dapat dilihat pada Gambar 3.

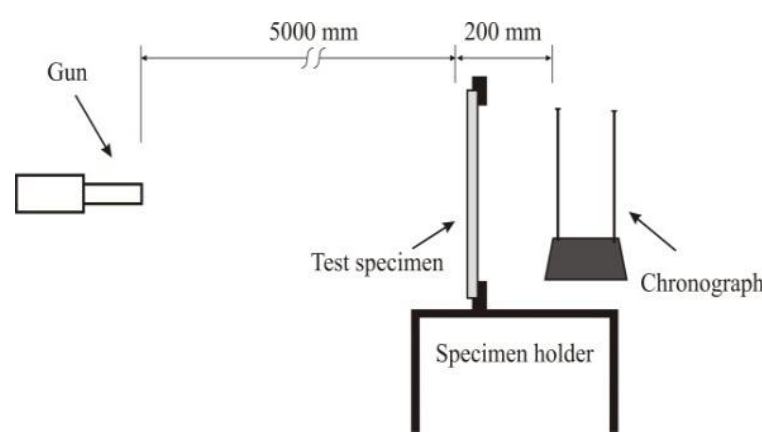

Gambar 3. Skema pengujian balistik

\section{HASIL DAN PEMBAHASAN}

Pengujian analisa struktur mikro menggunakan perbesaran $200 \mathrm{kali}$, pengujian mikro meliputi pilinan kulit eceng gondok tanpa dilakukan perendaman $\mathrm{NaOH}$ dan dilakukan perendaman $\mathrm{NaOH}$ selama 1 jam. Hasil analisa struktur mikro kulit eceng gondok dapat dilihat pada Gambar 3. 

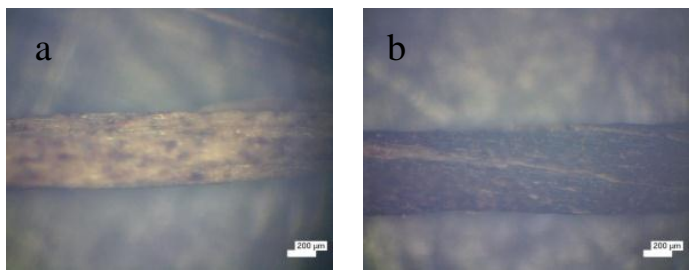

Gambar 3. Kulit eceng gondok yang dipilin (a).Sebelum perendaman $\mathrm{NaOH}$ (b). Sesudah perendaman $\mathrm{NaOH}$

Gambar 3 adalah hasil foto mikro kulit eceng gondok yang dipilin tanpa perendaman $\mathrm{NaOH}$ dan dilakukan perendaman $\mathrm{NaOH}$ selama 1 jam, kulit eceng gondok tanpa perendaman $\mathrm{NaOH}$ berwarna putih cenderung kuning keemasan yang menunjukkan adanya kotoran dan lignin yang terdapat pada kulit eceng gondok. Perbedaan kulit eceng gondok yang sudah dilakukan perendaman $\mathrm{NaOH}$ kulit eceng gondok berwarna kuning cenderung hitam, yang menunjukkan bahwa pada saat perendaman campuran $\mathrm{NaOH}$ dengan pelarut aquadest membuat temperaturnya menjadi meningkat yang mengakibatkan lignin pada kulit eceng gondok terangkat dan berkurang. Kulit eceng gondok yang dipilin seperti pada Gambar 3, bentuk pilinan tersusun rapat, tidak renggang dan membentuk susunan tunggal dengan massa jenis kulit $1 \mathrm{gr} / \mathrm{cm}^{3}$

Dimensi pilinan enceng gondok seperti diperlihatkan pada Gambar 4.
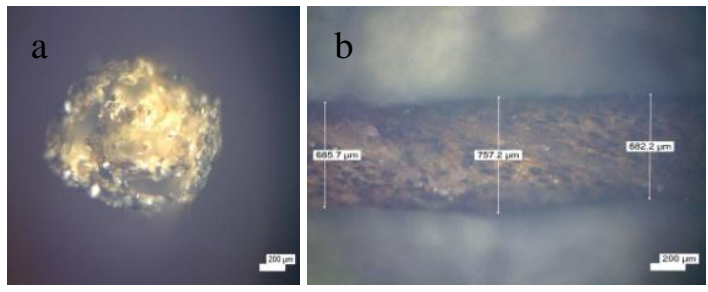

Gambar 4. Penampang diameter (a).Tampak atas (b). Tampak samping

Data hasil kulit eceng gondok yang dipilin tanpa perendaman $\mathrm{NaOH}$ dan perendaman $\mathrm{NaOH} \quad 5 \%$ selama 1 jam didapatkan hasil grafik perbandingan tegangan tarik rata-rata seperti disajikan dalam gambar 5 .

Hasil uji tarik serat tunggal pada kulit eceng gondok yang dipilin menunjukkan tegangan tarik sesudah perendaman $\mathrm{NaOH} 5 \%$ lebih tinggi yaitu $3,5512 \mathrm{~kg} / \mathrm{mm}^{2}$, dibandingkan tanpa perlakuan perendaman $\mathrm{NaOH}$ yaitu $2,0756 \mathrm{~kg} / \mathrm{mm}^{2}$. Hasil ini menunjukkan dengan perlakuan perendaman $\mathrm{NaOH} 5 \%$ kulit eceng gondok yang dipilin menjadi lebih kuat pada pengujian uji tarik serat tunggal.

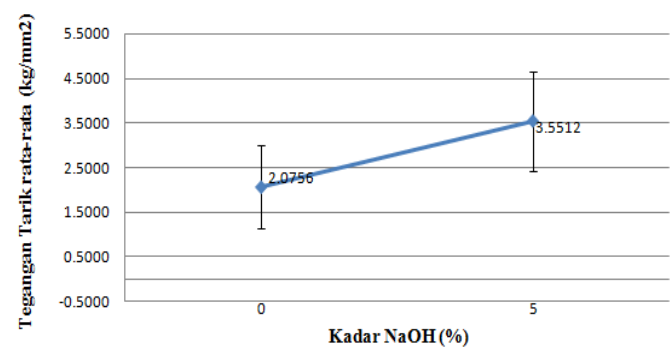

Gambar 5. Perbandingan antara tanpa perendaman $\mathrm{NaOH}$ dan perendaman $\mathrm{NaOH}$ $5 \%$

Pengujian tarik matrik resin tanpa penguat kulit eceng gondok dan komposit berpenguat kulit eceng gondok $11 \%$ didapatkan kekuatan tarik, regangan dan modulus elastisitas, dapat dilihat pada Tabel 1. Sedangkan kekuatan tarik dapat dilihat pada Gambar 6.

\section{Tabel 1. Perbandingan hasil pengujian tarik} matrik.

\begin{tabular}{|c|c|c|c|}
\hline $\begin{array}{c}\text { Fraksi } \\
\text { volume }\end{array}$ & 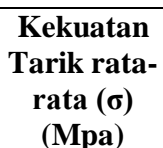 & $\begin{array}{c}\text { Regang } \\
\text { an rata- } \\
\text { rata }(\varepsilon) \\
(\%)\end{array}$ & $\begin{array}{c}\text { Modulus } \\
\text { Elastisitas } \\
\text { rata-rata } \\
\text { (MPa) }\end{array}$ \\
\hline $\begin{array}{l}\text { 0\% (Tanpa } \\
\text { Penguat Kulit } \\
\text { Eceng } \\
\text { Gondok) }\end{array}$ & 51,99 & 12,28 & 45,08 \\
\hline $\begin{array}{l}11 \% \\
\text { (Berpenguat } \\
\text { Kulit Eceng } \\
\text { Gondok) }\end{array}$ & 30,33 & 9,04 & 27,34 \\
\hline
\end{tabular}

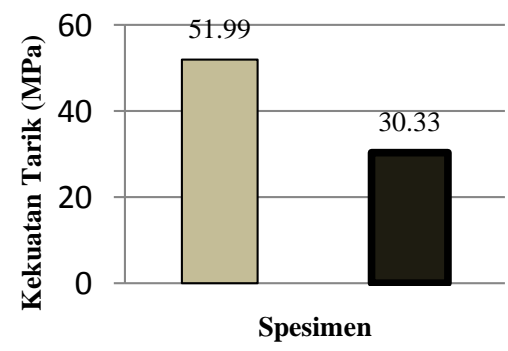

Gambar 6. Hubungan presentase kulit eceng gondok dengan kekuatan tarik

Berdasarkan hasil pengujian uji tarik komposit didapatkan data seperti Tabel 1 . Terlihat bahwa setiap bahan memiliki kekuatan tertentu, baik kekuatan tarik, regangan maupun 
modulus elastisitas. Gambar 6 menunjukkan kekuatan komposit. Sebelum ada penambahan pengisi pada resin, yang kekuatan tariknya sebesar 51,99 $\mathrm{MPa}$. Setelah adanya penambahan pengisi berupa kulit eceng gondok $11 \%$ kekuatan tariknya menurun yaitu 30,33 MPa. Hal ini disebabkan karena matrik resin tanpa penguat kulit eceng gondok lebih padat dan sedikit menimbulkan void, sebaliknya komposit dengan penguat kulit eceng gondok $11 \%$ lebih mudah terjadi void, diperkiran pada saat menyetak terjadi gelembung udara masuk pada sela-sela anyaman.

Pengujian balistik dilakukan dengan cara menembak 1 panel komposit sebanyak 3 kali dengan jarak $5 \mathrm{~m}$. Data hasil pengujian balistik dapat dilihat pada Tabel 2.

Tabel 2. Hasil Uji Balistik.

\begin{tabular}{|c|c|c|c|}
\hline $\begin{array}{c}\text { Fraksi } \\
\text { ketebalan } \\
\text { serat dan } \\
\text { resin 11: } \\
89 \%\end{array}$ & $\begin{array}{c}\text { Kecepatan } \\
\text { peluru rata- } \\
\text { rata }(\mathrm{m} / \mathrm{s})\end{array}$ & $\begin{array}{c}\text { Kondisi } \\
\text { panel }\end{array}$ & $\begin{array}{c}\text { Kecepatan sisa } \\
\text { pecahan/proyektil } \\
(\mathbf{m} / \mathbf{s})\end{array}$ \\
\hline \multirow{3}{*}{$3 \mathrm{~mm}$} & \multirow{3}{*}{200,7} & Tembus & 142 \\
\hline & & Tembus & 0 \\
\hline & & Tembus & 137 \\
\hline \multirow{3}{*}{$6 \mathrm{~mm}$} & \multirow{3}{*}{200,7} & $\begin{array}{l}\text { Tidak } \\
\text { tembus }\end{array}$ & 0 \\
\hline & & Tembus & 35 \\
\hline & & $\begin{array}{l}\text { Tidak } \\
\text { tembus }\end{array}$ & 35 \\
\hline \multirow{3}{*}{$10 \mathrm{~mm}$} & \multirow{3}{*}{200,7} & $\begin{array}{l}\text { Tidak } \\
\text { tembus }\end{array}$ & 0 \\
\hline & & $\begin{array}{l}\text { Tidak } \\
\text { tembus }\end{array}$ & 0 \\
\hline & & $\begin{array}{l}\text { Tidak } \\
\text { tembus }\end{array}$ & 0 \\
\hline
\end{tabular}

Tabel 2 menunjukkan panel komposit dengan ketebalan $3 \mathrm{~mm} 3$ kali tembakan dapat tertembus proyektil, ketebalan $6 \mathrm{~mm} 3$ kali tembakan 2 tidak tembus dan 1 tembus, dan panel dengan ketebalan10mm 3 kali tembakan tidak tertembus dan mampu menahan laju proyektil. Sisa kecepatan proyektil pada panel dengan ketebalan $3 \mathrm{~mm}$ adalah 142, 0 dan 137 $\mathrm{m} / \mathrm{s}$ dan pada panel dengan ketebalan $6 \mathrm{~mm}$ adalah 0, 35 dan $35 \mathrm{~m} / \mathrm{s}$. Panel dengan ketebalan $10 \mathrm{~mm}$ mampu menahan laju poyektil. Dengan ketebalan $10 \mathrm{~mm}$ panel mampu menyerap energi impak peluru walaupun pada sisi belakang panel mengalami retakan atau rusak. Retakan panel pada sisi belakang berupa garis retak seperti pada Gambar 7.

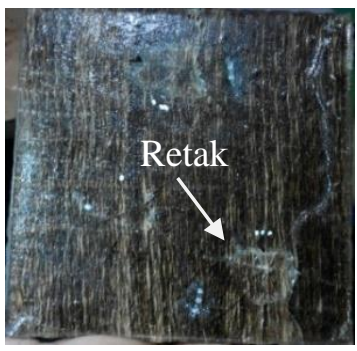

\section{Gambar 7. Retakan sisi belekang spesimen komposit ketebalan 10 mm}

Hal ini dipengaruhi oleh ketebalan komposit karena semakin tebal panel maka semakin tahan terhadap peluru (Nopriantina dan Astuti, 2013), tetapi semakin tebal panel akan berdampak pada berat rompi. Tebal minimum komposit kulit eceng gondok untuk ketahanan senapan angin jenis sharp innova dengan peluru berbentuk dome adalah $6 \mathrm{~mm}$.

\section{KESIMPULAN}

Dari hasil penelitian pengaruh ketebalan matrik resin dengan penguat kulit eceng gondok yang di anyam terhadap kemampuan balistik dapat diperoleh kesimpulan sebagai berikut:

1. Struktur mikro permukaan kulit eceng gondok cenderung berbentuk silinder sehingga penampang pilinan kulit berbentuk lingkaran dan massa jenis kulit adalah $1 \mathrm{gr} / \mathrm{cm}^{3}$. Kulit berwarna kuning cenderung hitam setelah perendaman $\mathrm{NaOH}$ selama 1 jam. Dari hasil pengukuran rata-rata diameter kulit eceng godok adalah $0,6667 \mathrm{~mm}$ dan kekuatan tarik rata-rata kulit eceng gondok adalah $3,5512 \mathrm{~kg} / \mathrm{mm}^{2}$. Hasil kekuatan tarik rata-rata komposit yaitu resin tanpa penguat kulit eceng gondok sebesar 51,99 $\mathrm{MPa}$ dan resin dengan penambahan kulit eceng gondok $11 \%$ kekuatan tariknya 30,33 MPa.

2. Hasil pengujian balistik memperlihatkan bahwa panel komposit dengan ketebalan 3 $\mathrm{mm}$ dan $6 \mathrm{~mm}$ dapat tertembus proyektil, sedangkan panel dengan ketebalan $10 \mathrm{~mm}$ mampu menahan laju proyektil. sehingga hasil yang paling optimal untuk panel komposit kulit eceng gondok. Dimana pengujian balistik menggunakan senapan agin jenis sharp innova dengan peluru jenis dome kal 4,5 dengan berat 0,54 gr adalah minimum ketebalan $6 \mathrm{~mm}$. Semakin tebal 
panel komposit maka semakin mampu menahan laju balistik tetapi berdampak pada berat panel akan semakin besar.

\section{DAFTAR PUSTAKA}

Gibson F, Ronald., 1994. Principle Of Composite Material Mechanics. Departemen Of Mechanical Engineering Waine State University Detroit, Singapore.

Moeliono. M dan Siregar. Y 2012. "Rekayasa Bahan Baku Sutera Dan Limbah Kokon Untuk Rompi Tahan Peluru (The Engineering Of Silk Material And Cocoon Waste For Ballistic Proof)'.' Jurnal Riset Industri, Vol. 06, Balai Besar Tekstil, Bandung.

NIJ-0101.04. 2001. Ballistic Resistance of Personal Body Armor. U.S. Department of Justice, Amerika.

Noni Nopriantina, Astuti., 2013. "Pengaruh Ketebalan Serat Pelepah Pisang Kepok (Musa Paradisiaca) Terhadap Sifat Mekanik Material Komposit Poliester Serat Alam”. Jurnal Fisika Unand, Vol. 02, Jurusan Fisika FMIPA, Universitas Andalas, Padang.

Prasetyaningrum A., 2009. "Optimasi Proses Pembuatan Serat EcengGondok Untuk Menghasilkan Komposit Serat Dengan Kualitas Fisik dan Mekanikyang Tinggi”. Jurnal RIPTEK, Vol. 03, Teknik Kimia, Universitas Diponegoro, Semarang.

Yudo. H dan Kiryanto., 2007. "Analisa Teknis dan Ekonomis Penggunaan Serat Ijuk Sebagai Alternatif Bahan Komposit Pembuatan Kulit Kapal Ditinjau Dari Kekuatan Tarik". Jurnal Teknik Perkapalan, Fakultas Teknik, Universitas Diponegoro, Semarang.

Zubaidi, Moekarto M, Santoso S., 2009. "Pembuatan Rompi Anti Peluru Menggunakan Bahan Dasar Serat Poliester”. Jurnal Arena Tekstil, Vol. 24, Balai Besar Tekstil, Bandung. 